\title{
FORUM
}

\section{A Transferred Radar Plot}

\author{
L. W. J. Fifield
}

DESPITE the fact that there is a large number of plotting aids available there must be many vessels in which radar plotting for anti-collision purposes remains a drawing exercise (transferred plotting), or is not attempted because it is believed to be a process too lengthy for the exigencies of practical work.

Quoting J. R. Webster of the Board of Trade-'Most of the collisions which have occurred have been in conditions when there were no other ships in the close-quarter situation, and in my opinion the relative display is better for judging the degree of collision risk in this case, with a simple plot to ascertain the effective avoiding action'. 1

Believing this to be so, the following suggestion is made for simplifying plotting procedure.

The information used in the plot should not require conversion in the timedistance-speed sense and this should apply to the information derived from the plot. The plot should enable the navigator to answer these questions:

i. Will a collision take place if present courses and speeds are maintained?

ii. What will be the distance off at nearest approach of the target even if there is no collision?

iii. What alteration of course and/or speed is required in order that this distance off can be increased to some safe value?

iv. What time is available for action?

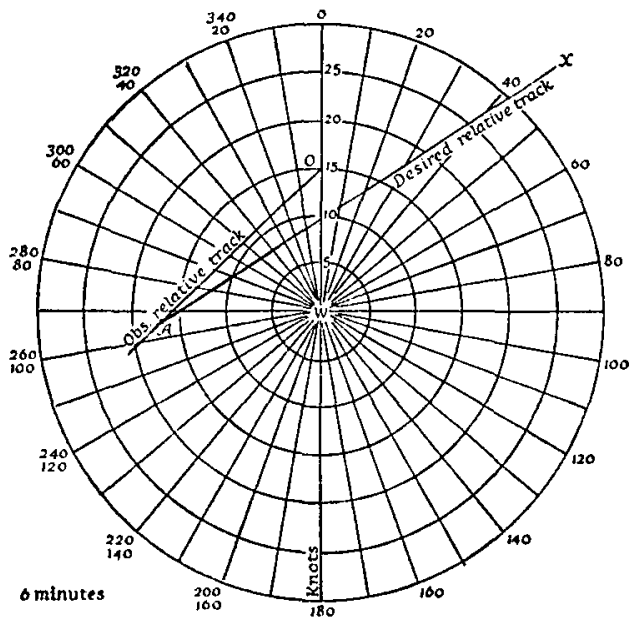

FIG. I
A simple relative plot readily gives the answers to $i$. and ii. and gives a good approximation to iv. To get an answer to iii. requires a certain amount of drawing. The amount of drawing and the need to convert speeds into distances can be minimized if a fixed plotting interval is used. Again, if the drawing begins from the centre of a compass rose surrounded by speed rings (instead of range rings), so that tracks and speeds can be seen by inspection, plotting is simplified.

In Fig. I a target on the starboard bow has been plotted on 
a standard radar plotting sheet at two instants of time $\left(t_{0}\right.$ and $\left.t_{6}\right)$, own vessel proceeding $000^{\circ}$ at fifteen knots. The relative track so found either passes clear or constitutes a threat. In the former case no further plotting need be done: subsequent echoes can be monitored on the PPI. In the latter case, the relative track is transferred to a prepared diagram (Fig. 2), where it is laid off from own vessel's course line $\left(000^{\circ}\right)$, at the appropriate speed ring ( 15 knots). The relative distance between the echoes is marked off as $O A$, on the diagram. A desired relative track-from the last position of the echo tangential to the two-mile range ring (say)-is also transferred to the diagram in the reverse sense (AX). Any intersection of $\mathrm{AX}$ with a radius gives a course and speed to achieve the required relative track. By inspection, an alteration of course of about $25^{\circ}$ to starboard is needed if speed is maintained or a reduction of speed to about ro knots will suffice if course is maintained. Any combinations of course and speed can also be seen at a glance-for ex-

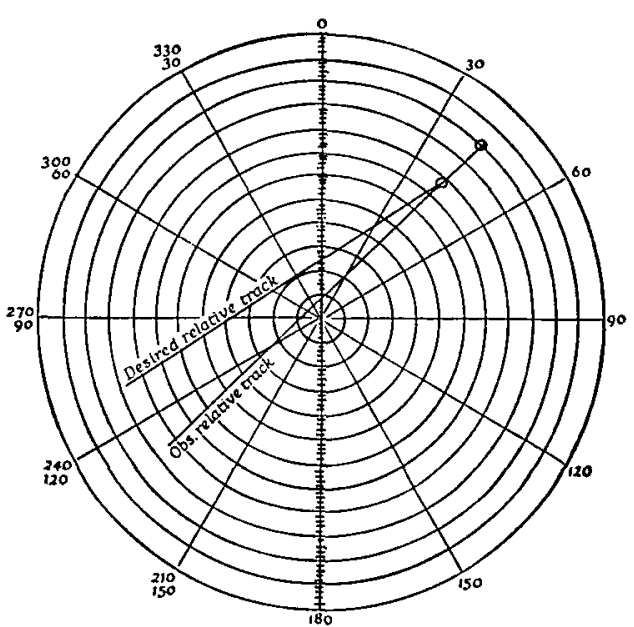

FIG. 2 ample, an alteration of only $10^{\circ}$ requires a reduction to about is knots.

In this diagram the symbols $O, A$ and $W$ have their usual connotation. $O W$ is the distance steamed by own vessel at 15 knots-to the appropriate scale. It should be noted that no measurements have to be made-direction and length are simply transferred using rulers and dividers. Extracting the required information by inspection achieves all the accuracy warranted by the data since any form of plotting hinges upon the initial observations of bearings and distances.

Application: The prepared diagram could be included in the centre of a standard plot but this tends to confusion of lines after a while and in any case, for clarity, it is desirable to expand the scale of the diagram without making the standard plot too large. For this reason a plotting sheet was formed using a twelve-inch diameter standard relative plotting sheet representing a twelve-mile range scale, flanked by four approximately six-inch diameter circles. These latter were graduated radially at $\mathrm{o} 0$-degree intervals and in lieu of range rings, speed rings were marked off in knots. Each of the smaller circles is effectively twice the scale of the standard plot and each one is graduated for speed appropriate to a given interval: intervals of $4,5,6$ and 8 minutes were chosen as being suitable for most purposes (Fig. 3).

Plotting procedure: This would be facilitated by using a re-set timer and a pair of proportional dividers. For use with the plot as a twelve-mile range scale the dividers would be set two to one-if it was desired to double the scale of the standard plot the proportion would be one. 

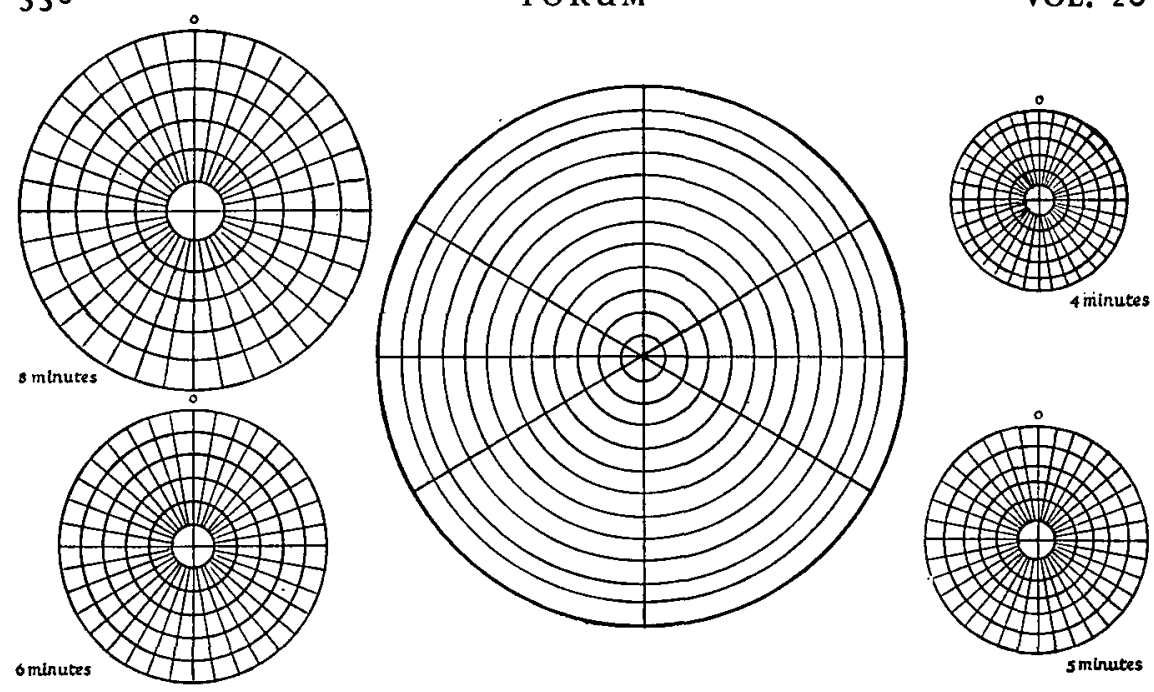

FIG. 3. The proposed plot

Routine: With standard plot as a 12 -mile range scale, ships head up, plotting interval of 6 minutes, the routine would be:

i. Standard plot: plot range and bearing of echo, set timer.

ii. Standard plot: time signal, plot range and bearing of echo.

If necessary:

iii. Transfer relative track to the 6-minute diagram. Transfer the relative distance to the 6-minute diagram (double scale using dividers).

iv. Transfer desired avoidance track to the diagram in reverse sense.

v. Extract the required alteration from the diagram by inspection.

There could be divergence of opinion regarding the choice of plotting interval. Four minutes may be suitable for high speed vessels closing end-on: 8 minutes or longer would be suited to the overtaking situation. Additional plots of the echo could be made within the chosen interval in order to verify the line of approach. Nevertheless, acceptance of this limitation on the choice of interval eliminates the need for mental arithmetic and measurement and reduces the work to the plotting of the two (or three) positions of the echo and the drawing of the two lines OA and AX (Fig. I), since the lines on the standard plot need not necessarily be drawn in. The other vessel's course and speed can be seen by inspection from the diagram, if required. In Fig. I, for example, the other vessel is heading about $275^{\circ}$ at 17 knots.

Although the diagram has been drawn 'ship's head up' (since my own predeliction is for a stabilized presentation of this sort, for collision avoidance) it could equally be drawn 'north up'. Suitable diagrams for this purpose, measuring about $15^{\prime \prime}$ by $30^{\prime \prime}$, could be produced, of similar quality to the standard Radar Plotting Sheet (H.M.S.O.).

Finally, it is worth quoting again from this Journal _. . . some form of plotting is essential unless circumstances preclude it: this is denied by some who depend 
solely on their mental processes. Collision statistics show that, among the unsuccessful, they are in a great majority.' 2

\title{
REFERENCES
}

1 Webster, J. R. (1962). Discussion. This Journal, 15, 272.

2 Wylie, F. J. (1966). True motion and relative motion. This Journal, 19, 32.

\section{Collisions in Western European Rivers}

\author{
Captain Archie Horka \\ (Master, United States Lines, Ret.)
}

Captain A. Wepster's able and professional analysis of this subject, contained in the January issue of the Journal, confirms what many seamen have long known. That these rivers-the Schelde, the New Waterweg, the Weser and, finally, the teeming Elbe, from Brunsbuttel seaward-are the world's most difficult and demanding stretches of navigation for seamen and pilots. The Captain's excellent treatment focuses attention on this and in his final paragraph he offers several considerations which, if followed, could reduce the number of collisions.

I refer to page 29; 'Improving River and Port Authority Organizations and, if necessary, traffic control. On page 17, with reference to changing pilots in Flushing Roads in the Schelde; who has not, when proceeding outbound, 'overshot' the mark when approaching the pilot ground off the Commercial Harbour? There follows the business of making a complete circle midst moving traffic as an apologetic pilot comes a puffing to the bridge, showering abuse on the man he relieved because 'he failed to slow down in time'.

I would add a specific recommendation to those offered by Captain Wepster: For vessels outbound from the Schelde, to disembark their pilots and take on Oostgat or Wandelaar pilots at a point approximately three miles upriver, say at Sloehaven. A pilot station could be maintained at that point in the manner of the present pilot office at the Flushing Mole. Under the present system, say with an ebb tide under your stern, the cutter emerges from beyond the breakwater after an agonizing wait at which your pilot gives you a breezy wave and a 'Cheerio, Captain. The boat is coming. I go down now?' Unless you are a martinet, you mutter an assent and find yourself 'Queen of the May', literally in command of 'all you survey'. The pilots, meanwhile, are cheerily relieving one another at the ladder whilst you, drifting down on to the Nolle, are undecided whether to jump overboard or go blind!

Innumerable reasons would be presented why the status quo must prevail but a change is long overdue here. Lacking that, we must resign ourselves to a continuation of this 'Hurrah's Nest' that now prevails in Flushing Roads. 